\title{
Feasibility of Gracilis Muscle Flap Interposition for Management of Recurrent Rectovesical/Rectourethral Fistulas: A Single Centre Expertise
}

\author{
Ahmed Hossamedine Abdou Achim Troja Hans-Rudolph Raab Dalibur Antolovic
}

Department of General and Visceral Surgery, Klinikum Oldenburg, Germany

Keywords

Recurrence · Rectovesical fistulas · Gracilis muscle flap

\section{Summary}

Background: Recurrent rectovesical fistulas are a serious burden for the affected patient. Depending on the size and location of the fistula, the underlying disease as well as the preceding therapies, a definitive surgical treatment of the fistula should be the main goal. We analysed the technique of the transposition of the gracilis muscle as a therapeutical option. Methods: We analysed data from 3 male patients who were diagnosed with a recurrent rectovesical fistula and were treated by the transposition of the gracilis muscle in the surgical department of Klinikum Oldenburg. Results: All 3 patients suffered from prostate cancer and were already treated by a different surgical approach while one patient had a second recurrence. Complications arose in two cases in the form of fistula recurrence. Conclusion: Our study has shown that the interposition of the gracilis muscle provides an option to treat rectovesical fistulas.

\section{Introduction}

Fistulas between the rectum and the urethra have different aetiologies. Rarely, they may be congenital. In most cases, they are acquired as the result of infection, inflammation, neoplasia, or trauma [1,2]. In addition, iatrogenic fistulas are possible after radiotherapy and pelvic surgery, especially for the treatment of prostate cancer [3].

\section{KARGER}

Fax +497614520714

Information@Karger.com

www.karger.com (c) 2013 S. Karger GmbH, Freiburg

$1662-6664 / 13 / 0294-0250 \$ 38.00 / 0$

Accessible online at:

www.karger.com/vim
Schlüsselwörter

Rezidiv · Rektovesikale Fisteln · Lappenplastik des Musculus gracilis

\section{Zusammenfassung}

Hintergrund: Rektovesikale Rezidivfisteln sind ein ernsthaftes Problem für die betroffenen Patienten. Abhängig von der Größe und dem Ort sowie der Grunderkrankung und den vorangegangenen Therapien ist die definitive chirurgische Sanierung die Therapie der Wahl. Wir analysierten die Technik der Transposition des Gracilis-Muskels als eine therapeutische Option. Methoden: Wir untersuchten Daten von 3 männlichen Patienten, die die Diagnose einer rektovesikalen Rezidivfistel bekommen hatten und mittels Transposition des Musculus gracilis behandelt wurden. Ergebnisse: Alle 3 Patienten waren an einem Prostatakarzinom erkrankt und und waren bereits an der Fistel operiert worden. Bei einem der Patienten bestand bereits das zweite Rezidiv. Zwei Patienten erlitten Komplikationen mit einem erneuten Fistelrezidiv. Schlussfolgerung: Die Daten zeigen, dass die Transposition des M. gracilis eine mögliche Therapieoption darstellt.

It is considered a complex fistula because it develops after radical prostatectomy, radiotherapy, cryotherapy, or combination therapy [4-6]. In most of these conditions, the fistula is usually large and the healing power of local tissues is poor. Although symptoms such as pneumaturia, faecaluria, and the passage of urine through the rectum are often alleviated by faecal and urinary diversion, these fistulas seldom heal spontaneously [7]. Even when diverted, patients may suffer from 
Table 1. Gracilis muscle flap interposition in 3 male patients for complex rectourethral/vesical fistulas

\begin{tabular}{llllllll}
\hline Patient & Age & Recurrence & Type of fistula & Underlying disease & Complications & Success & Time span \\
\hline 1 & 65 & first recurrence & rectovesical & prostate cancer & yes & yes & 65 months \\
2 & 77 & second recurrence & rectovesical & prostate cancer & no & yes & 66 months \\
3 & 55 & first recurrence & rectovesical & prostate cancer & yes & no & 48 months \\
\hline
\end{tabular}

urinary tract infections, which can prove resistant to medical therapy [8]. Thus, most of these patients will eventually require surgical treatment.

A variety of surgical options has been described, including mucosal flaps, instillation of fibrin glue, and proctectomy [9-11]. The gracilis muscle flap is another option for the repair of fistulas. The flap has an adequate length, can be rotated easily into the perineum, and brings well-vascularised muscle to irradiated or traumatised tissue. It serves as a mechanical barrier between the urethra or vagina and the rectum [12]. Multiple surgical repairs are often required to heal these types of fistulas [9-11].

We performed a retrospective analysis of all patients who underwent the gracilis muscle flap interposition at our hospital for the repair of fistulas between the rectum and the urethra or the bladder arising from different aetiologies from September 2007 to March 2013. Due to the relative rarity of the occurrence of rectourethral fistula, we would like to present our centre experience with 3 patients who underwent this procedure in our hospital.

\section{Patients and Methods}

We performed the gracilis muscle flap interposition in 3 male patients who had complex rectourethral/vesical fistulas resulting from radical prostatectomy by cancer of the prostate $(n=3)$. None of the patients had an adjuvant radiotherapy (table 1 ).

Preoperative assessment included voiding cystourethrogram, cystoscopy, proctoscopy, and computerized tomography of the pelvis. Some important factors were evaluated preoperatively in order to help plan the surgical approach and expect the outcome. These factors are fistula size and location, an associated urethral stricture, condition of the external urethral and anal sphincter, and the extent of local tissue damage.

An abdominoperineal approach was pursued in a single case, whereas a fistula closure was achieved via a perineal approach only in the other two cases.

Prior to flap closure of the fistula, 2 out of the 3 patients had faecal diversion via protective ileostomy. In one case, the faecal diversion was performed postoperatively because of the occurrence of complications in the form of repair insufficiency.

\section{Flap Harvest Technique}

The gracilis is the most superficial muscle on the medial side of the thigh. It arises from the symphysis pubis and inferior pubic ramus, and runs vertically downward to insert into the upper part of the medial surface of the tibial body. Its neurovascular pedicle is situated approximately $4 \mathrm{~cm}$ below the lateral edge of the pubic ramus. In more than $95 \%$ of patients, 1-3 perforating vessels enter the lateral aspect of the gracilis. Fortunately, in $90 \%$ of patients, these perforating vessels can be safely ligated and divided without compromising the muscle blood supply.

The patients were positioned in the lithotomy position. The left gracilis muscle was always used. Initially, the mobilisation of the gracilis muscle was performed by an incision at the medial thigh behind the saphenous vein. The dissection of the muscle takes place in the area of the pes anserinus, and the perforating vessels are ligated. The next step was to identify the neurovascular bundle, which was spared to protect the vascularisation of the tissues. One must then measure the length of the mobilised muscle flap in order to position it in the perianal spatium, after which the perineal incision is done and the delicate perirectal dissection is performed. We recommend performing the dissection up to $2 \mathrm{~cm}$ proximal to the defect in order for it to be safely covered by the gracilis flap. The fistula was excised in total and primarily closed by a suture. The transpositioned muscle was fixed in its position with multiple sutures. The perineal wound was adapted with a small triangular spot for a drain. The patients were advised to ensure not to use their leg adductors for the first 3 days postoperatively [13].

All the patients were followed up over a time period ranging from 24 to 36 months postoperatively. Postoperative assessment was performed via a telephone interview, where the patients answered a previously prepared questionnaire assessing the success of the repair by asking about absence of the commonly associated complaints, e.g., urinary tract infection, faecaluria or leakage of urine per rectum, wound healing (perineal and donor site morbidity) as well as faecal and urinary continence.

Ileostomy closure was performed successfully in 2 patients.

\section{Results}

Between 2007 and 2013, 3 patients diagnosed with rectovesical fistulas underwent a gracilis muscle flap interposition (table 1). Protective ileostomy was performed preoperatively in 2 patients and postoperatively in 1 patient due to recurrence of fistula-related complaints.

In one patient, our repair was performed at the second recurrence after two unsuccessful attempts which had been carried out in another hospital. Complications arose in 2 cases in the form of fistula recurrence. In 1 case, which did not obtain a protective ileostomy preoperatively, however, a good healing of the fistula was achieved after a subsequent ileostomy was performed. The other case had to have a permanent faecal diversion in the form of colostomy.

Regarding the evaluation of the data, predictive criteria for the failure of the treatment of a rectovesical fistula with a gracilis muscle flap could not be established due to the small number of patients included in the study.

\section{Discussion}

The gracilis muscle has been used as a rotation flap or for various purposes without a significant effect on lower limb strength and range of motion. In colorectal surgery, it has been used to construct a neosphincter around the anus in patients with faecal incontinence [14]. 
Using gracilis transposition to treat rectovesical fistulas was described in 1979 by Ryan et al. [15]. Nyam and Pemberton [7] suggested that gracilis muscle transposition had a better success rate than other types of rectourethral fistula repair but their experience was based on 3 cases with a success rate of $100 \%$.

The basic principle is to bring viable tissue to interpose between rectum and urethra. The plane between these two organs is dissected, the fistula is divided, and the rectal and urethral defects are repaired. A viable tissue flap is then transposed to separate the rectum from the urethra. Several types of tissue flaps may be used. The greater omentum is an option; however, this procedure involves laparotomy and deep anterior pelvic dissection. It may not be feasible in patients who have undergone previous abdominal surgeries. Transposition of the gracilis muscle as a viable flap provides a wellvascularised muscle rotation flap, thereby avoiding the need for laparotomy [16].

In 2003, Zmora et al. [2] described the gracilis muscle transposition for iatrogenic rectourethral fistulas in 11 patients after surgery or pelvic radiotherapy for prostate cancer.
The advantage of the flap is its close location to the defect and good blood supply from the branches of the profunda femoris artery. The complication rate after the muscle transposition is generally minimal.

\section{Conclusion}

Our study has shown that the interposition of the gracilis muscle provides a good option to treat rectovesical fistulas. Furthermore, it is associated with low donor site morbidity. Due to the small number of patients included in the study, we are not able to show any predictive criteria for a successful repair. However, we do recommend the need for bowel diversion before attempting reconstruction.

\section{Disclosure Statement}

The authors of this manuscript have no conflicts of interest to disclose.

\section{References}

1 Boushey RP, McLeod RS, Cohen Z: Surgical management of acquired rectourethral fistula, emphasizing the posterior approach. Can J Surg 1998;41: 241-244.

2 Zmora O, Potenti FM, Wexner SD, Pikarsky AJ, Efron JE, Nogueras JJ, Pricolo VE, Weiss EG: Gracilis muscle transposition for iatrogenic rectourethral fistula. Ann Surg 2003;237:483-487.

3 Fengler SA, Abcarian H: The York Mason approach to repair of iatrogenic rectourinary fistulae. Am J Surg 1997;173:213-217.

4 Chrouser KL, Leibovich BC, Sweat SD, Larson DW, Davis BJ, Tran NV, Zincke H, Blute ML: Urinary fistulas following external radiation or permanent brachytherapy for the treatment of prostate cancer. J Urol 2005;173:1953-1957.

5 Izawa JI, Ajam K, McGuire E, Scott S, von Eschenbach AC, Skibber J, Pisters LL: Major surgery to manage definitively severe complications of salvage cryotherapy for prostate cancer. J Urol 2000;164:1978-1981.
6 Davis BJ, Pisansky TM, Leibovich BC: Adjuvant external radiation therapy following radical prostatectomy for node-negative prostate cancer. Curr Opin Urol 2003;13:117-122.

7 Nyam DC, Pemberton JH: Management of iatrogenic rectourethral fistula. Dis Colon Rectum 1999; 42:994-997.

8 Thompson IM, Marx AC: Conservative therapy of rectourethral fistula: five-year follow-up. Urology 1990;35:533-536.

9 Lewis MI: Gracilis muscle transplant for the correction of anal incontinence: report of a case. Dis Colon Rectum 1972;15:292-298.

10 Pickrell K, Georgiade N, Maguire C, Crawford H: Correction of rectal incontinence; transplantation of the gracilis muscle to construct a rectal sphincter. Am J Surg 1955;90:721-726.

11 Pickrell K, Georgiade N, Richard EF, Morris F: Gracilis muscle transplant for the correction of neurogenic rectal incontinence. Surg Clin North Am 1959;39:1405-1415.
12 Rist M, Krupp S, Rutishauser G: Gracilis flap plasty in the treatment of chronic pelvic infections following radiation therapy and cystoprostatectomy. Urologe A 1983;22:95-97.

13 Ruiz D, Bashankaev B, Speranza J, Wexner SD: Graciloplasty for rectourethral, rectovaginal and rectovesical fistulas: technique overview, pitfalls and complications. Tech Coloproctol 2008;12:277281; discussion 281-282.

14 Mander BG, Wexner SD, Williams NS, Bartolo DC, Lubowski DZ, Oresland T: Preliminary results of a multicenter trial of the electrically stimulated gracilis neoanal sphincter. Br J Surg 1999;86:15431548.

15 Ryan JA, Beebe HJ, Gibbons RP: Gracilis muscle flap for closure of rectourethral fistula. J Urol 1979; 122:124-125.

16 Sin PR, Foley E, Steers WD: Surgical management of rectourethral fistula. J Am Coll Surg 2000;191: $547-553$. 